\title{
Design and Analysis of Different Types of Rotors for Pico-Turbine
}

\author{
Samia Tabassum, Mashudur Rahaman, Muhammad Shahriar Bashar, Saidul Islam, \\ Afrina Sharmin, Abdullah Yousuf Imam, Azizul Hoque, Nahid Mahbub, Sayeda Khatun, \\ Mahfuza Khanam \\ Institute of Fuel Research and Development, Bangladesh Council of Scientific and Industrial Research, Dhaka, \\ Bangladesh \\ Email: shawon14@gmail.com
}

Received 12 April 2015; accepted 6 June 2015; published 9 June 2015

Copyright (C) 2015 by authors and Scientific Research Publishing Inc.

This work is licensed under the Creative Commons Attribution International License (CC BY). http://creativecommons.org/licenses/by/4.0/

(c) (i) Open Access

\begin{abstract}
Small-scale vertical axis wind turbine (VAWT) rotor is developed for use in areas lacking adequate energy infrastructure. The materials and methods of construction are selected to minimize cost as much as possible. The paper describes the design of different kinds of vertical axis wind turbine rotors having different number of blades and twist angle. The aim of the work is to study the influence of the different designs on rotational speed and power of rotor in different wind speed.
\end{abstract}

\section{Keywords}

Vertical Axis Wind Turbine, Savonius Rotor, Wind Energy, Power Co-Efficient

\section{Introduction}

The rising cost of fossil fuel and effects of climate change forces to enhance the demand of renewable energy sources in different sector. Like as other renewable energy sources, wind power has a key role in reducing greenhouse gas emissions [1]. Wind energy is a clean renewable energy source cheaper to maintain, saves fuel and can give decentralized energy [2]. A wind turbine is a device that taps the renewable kinetic energy of blowing wind, which converts it to useable mechanical, electrical or thermal energy. The main idea of wind power is to produce mechanical or electrical power economically without air pollution by using exhaustible natural resources. The function of a wind electric generator is to convert the kinetic energy of the wind into most useful form of energy i.e. electricity. The basic design requires the conversion done in the most efficient way and at lowest cost. This is done in few steps such as kinetic energy of the wind, converted through blades to mechanical energy of a rotating shaft and then transmitted through a gearbox to a generator, which converts the 
mechanical energy into electrical energy [3]. Today, the most commonly used wind turbine is the Horizontal Axis Wind Turbine (HAWT), where the axis of rotation is parallel to the ground. However, Vertical Axis Wind Turbine (VAWT), where, the axis of rotation is longitudinal to the ground is also an imperative issue in power generation sector. These devices can operate in flows coming from any direction, and take up much less space than a traditional HAWT [4], and VAWTs are definitely a credible source of energy for the future. VAWTs have a number of advantages over HAWTs, such as simple construction, low cost and can accept wind from any direction. In Bangladesh, wind speed is not so high and direction is highly variable [5]. That's the reason why vertical axis wind blade can be more effective for this country [6]. In this context, different types of vertical axis wind blade have been developed and analyzed [7]. A brief design description, details of the experiments conducted and the conclusions drawn are the prominent features of the present paper.

\subsection{Basic Principle of Savonius Wind Turbine}

Savonious wind turbine is vertical axis wind turbine (VAWT), which converts the force of the wind into torque on a rotating shaft. It is invented by the Finnish engineer Sigurd Johannes Savonius in 1922. The Savonius rotor consists of two (look like "S" shape in cross section) or three scoops. Because of the curvature, vertical axis wind turbines allow winds from any direction equally and force to rotate [8]. The savonius wind turbine works due to the difference in forces apply on each blade. The concave half part of the blade receives air and forces the blade to rotate around its central vertical shaft. At the same time, the convex half part of rotor hits the blade and causes the air to be deflected sideway around it, which is shown in Figure 1.

By placing two rotors on the same shaft, one designed to run clockwise and another one designed to run counter clockwise and exposing them to a flow, a significantly better performing rotor can be made. Both rotors should turn in the direction of the one with better starting characteristics. This type of vertical axis rotor is very robust and durable if built correctly, is relatively slow turning and can be easily built at home, without the hassles of aerofoil blade design and other problems associated with horizontal axis "propeller" type turbines.

\subsection{Design and Theory}

In this work, we have developed three different types of blade for investigating various properties. The first model (Blade-1), shown in Figure 2, is a twisted savonius with two helical blades arranged at $180^{\circ}$ around the shaft. GI wires (15 swg) were placed on shaft (aluminum pipe with diameter of $0.0127 \mathrm{~m}$ ) as frame of blade, which was covered by paper. Blade-2 is a drag-type savonius (Figure 3) made by plastic material. It has two sections. Each two-scoop would like an "S" shape in cross section. The two scoops in the top section of the rotor are rotated at $90^{\circ}$ to the bottom ones. This ensures that there is always at least one scoop in a position to catch the wind and as a result, the turbine is self-starting. The third one (Blade-3) is also a drag type savonius with three blades (Figure 4). Here, the blades are arranged at $60^{\circ}$ around the shaft. Each blade is triangular in shape and curved a bit with a support. GI sheets and aluminum pipe were used for the blades and shaft, respectively.

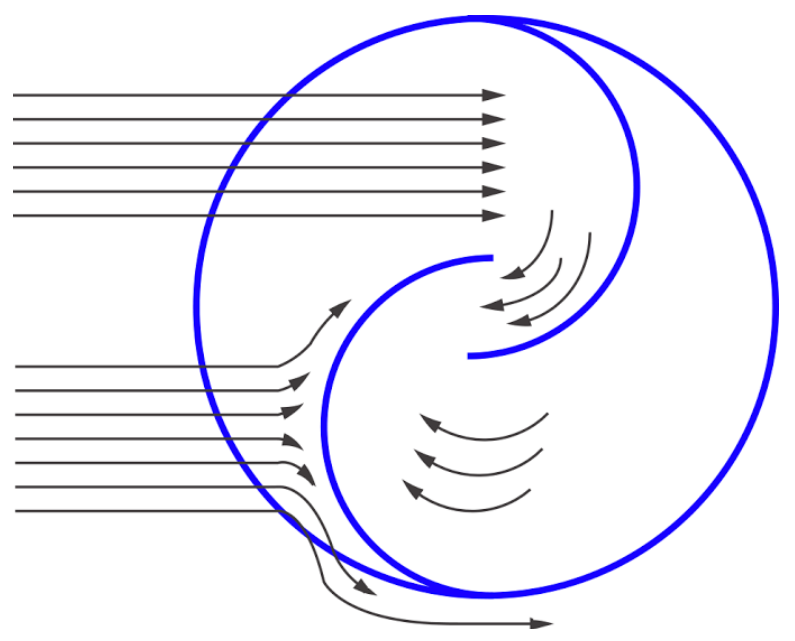

Figure 1. The effects of wind on savonius blade. 


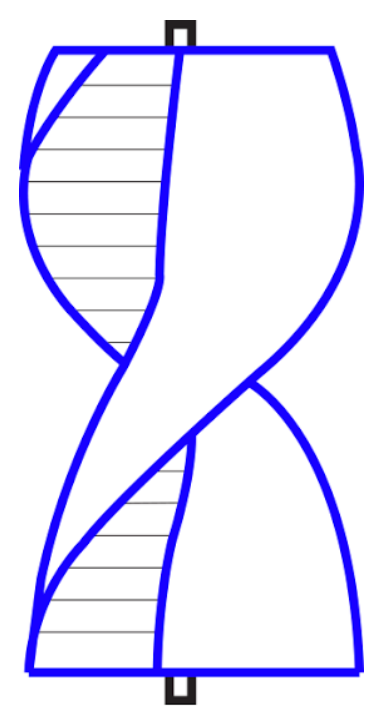

Figure 2. Twisted vertical axis blade (Blade-1).
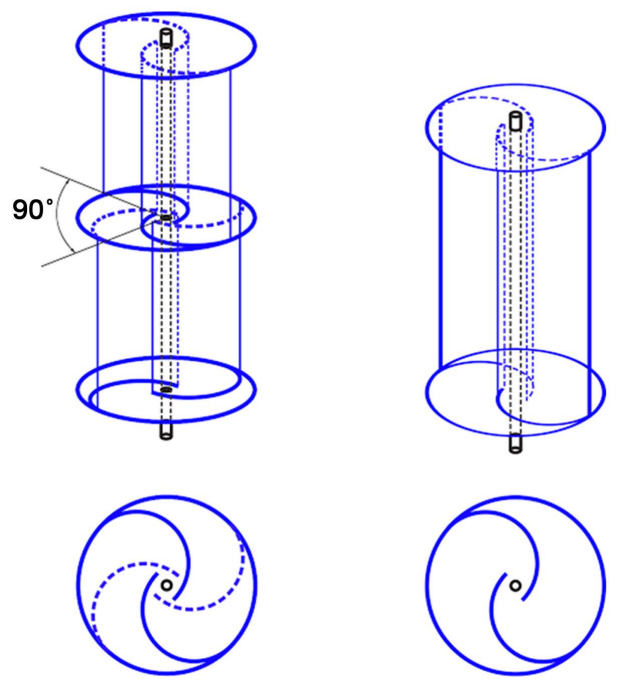

Figure 3. (a) Two steps savonius blade (Blade-2); (b) One step savonius blade.

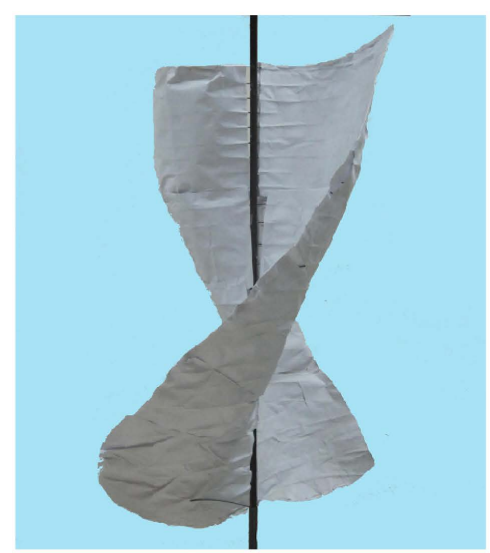

Blade-1

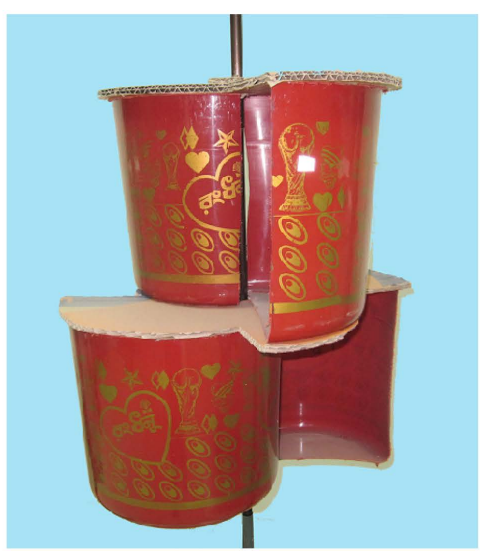

Blade-2

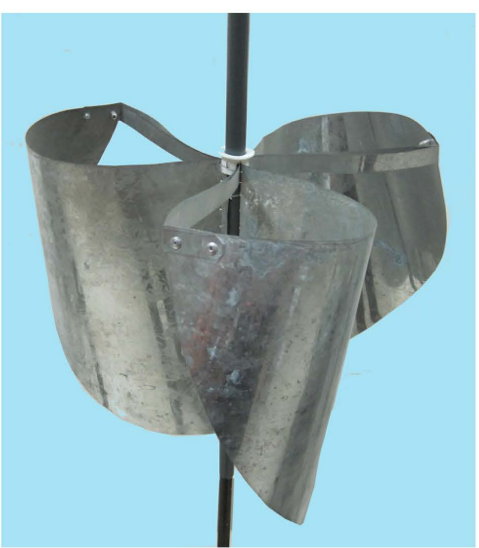

Blade-3

Figure 4. Picture of different designed blades. 
The amount of energy produced by a wind turbine primarily depends on the rotor area, also referred to as cross-sectional area, swept area, or intercept area. The swept area for savonius wind turbine can be calculated from the dimensions of the rotor

$$
\text { Swept area }=A=H^{*} D
$$

where, $H=$ rotor height; $D=$ rotor diameter.

The tip speed ratio, $\lambda$ is the ratio of the linear speed of rotor blade $\omega . R$ to the undisturbed wind speed; $V$. Here, $\omega$ is the angular velocity and $R$ represents the radius revolving part of the turbine. High tip speed ratio improves the performance of wind turbine and this could be obtained by increasing the rotational rate of the rotor.

$$
\lambda=\omega \cdot R / V \text {. }
$$

The power coefficient $\left(C_{p}\right)$ represents the amount of energy that can be harvested from the wind to convert it into mechanical energy. The power coefficient reaches its maximum for a unique tip speed ratio. It is the ratio of maximum power obtained from the wind to the total power available in the wind. This hypothesis shows the relationship between the power coefficient $\left(C_{p}\right)$ and the wind speed $(V)$, which expresses the basic theory of the Savonius wind turbine. Principally the power that the savonius rotor can extract from the wind $\left(P_{w}\right)$ is less than the actual available from the wind power $\left(P_{a}\right)$. The available power $\left(P_{a}\right)$, which is also the kinetic energy (KE) of the wind, can be defined as:

$$
\begin{aligned}
& P_{a}=1 / 2 m_{a} V^{2} \\
& P_{a}=1 / 2 \rho A V^{3}
\end{aligned}
$$

where, $m_{a}$ (wind mass flow rate striking the swept area of the wind turbine $(\mathrm{kg} / \mathrm{sec})$ ) $=\rho A V$.

$\rho$ is density of air, $A$ is the rotor area, $V$ is the speed of wind.

The power coefficient $\left(C_{p}\right)$ is given by:

$$
C_{p}=\frac{\text { Extracted power from the wind }}{\text { Available power of the wind }}=\frac{P_{w}}{P_{a}} \text {. }
$$

The extracted power from the wind of a wind turbine blade is determined by the following equation:

$$
P_{w}=0.5 \rho A V^{3} C_{p} .
$$

The fundamental laws of conservation of mass and energy allowed no more than 59\% of the kinetic energy of the wind to be captured which is well-known as Betz' law. Practically, wind turbines cannot operate at this maximum limit. The $C_{p}$ value is unique to each turbine type and is a function of wind speed that the turbine is operating in. In practice, values of obtainable power coefficients are in the range of $0.35-0.45$ common even in the best designed wind turbines. This value below the theoretical limit is caused by the inefficiencies and losses attributed to different configurations, rotor blades and turbine designs. The maximum power coefficient, $C_{p}$ for savonius rotor is 0.30 . Hence, the $C_{p}$ value used in this work is 0.30 [9]. However, density of air varies according to elevation, temperature and weather fronts. Density of air for $30^{\circ} \mathrm{C}$ is $1.16 \mathrm{~kg} / \mathrm{m}^{3}$ [10].

Wind speed was measured by cup anemometer (Lutron $\mathrm{ABH}-4224$ ) and rotor speed in rotation per minute (RPM) was measured by using laser type tachometer (Lutron DT-1236L). The data was taken at room temperature. Swept area and obtained wind power is also important aspects for this purpose and it is calculated as well.

The wind tunnel was built to have interchangeable parts to test different combinations of design parameters. Experiments were conducted in this wind tunnel. The schematic diagram of wind tunnel made by GI sheet is shown in Figure 5. The wind tunnel is $172 \mathrm{~cm}$ long, which consists of contraction section, test section and diffuser section. The first part is contraction zone to produce a uniform wind velocity distribution to the test section. Rotors are placed in front of anemometer in the test section, where, wind speed data and rotational speed of rotor is measured. The exhaust fan is driven to flow the wind in tunnel in the diffuser section.

\section{Results and Discussion}

The aim of this experimental study is to obtain the aerodynamic performance of studied wind turbine rotor and also the detailed information about velocity field around the rotor. Different types of blade is developed and placed in wind tunnel, where, rotational speed is measured in variation of wind speeds. Table 1 shows the summery of design parameters of blades. 


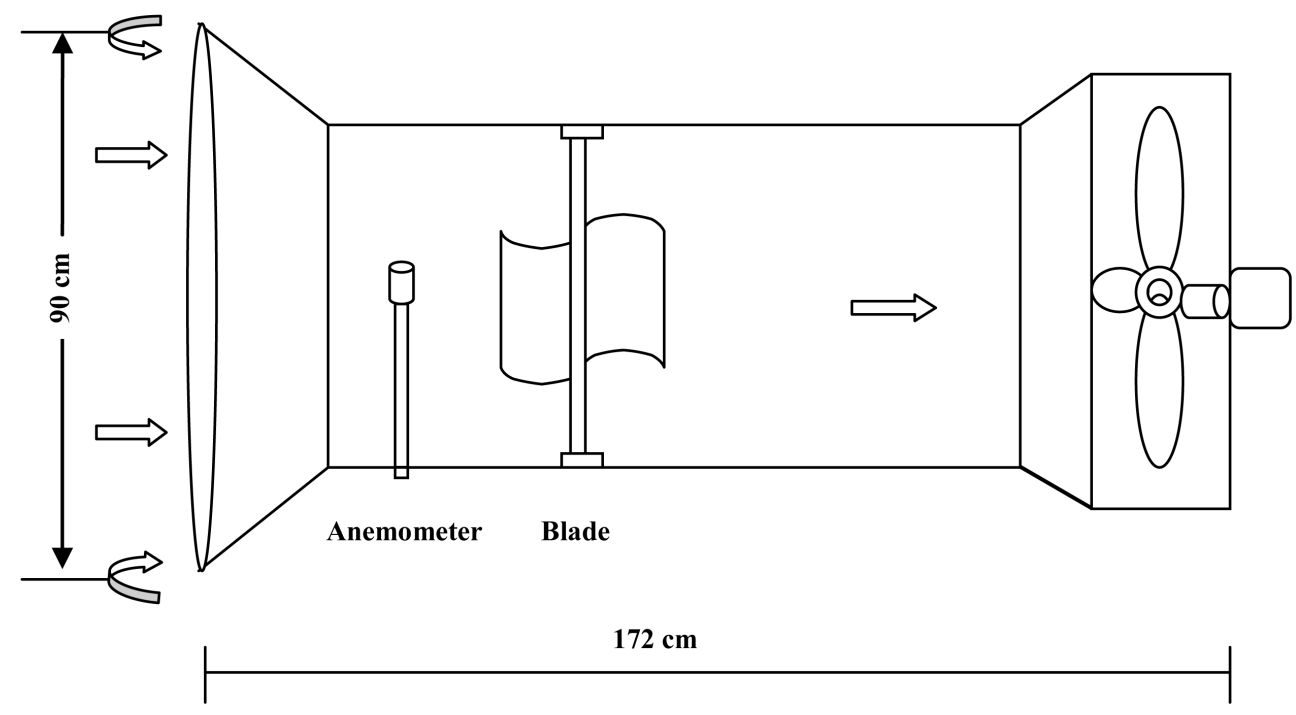

Figure 5. Schematic diagram of wind tunnel.

Table 1. Summary of design parameters of blades.

\begin{tabular}{ccccccc}
\hline Blade & Height $(\mathrm{m})$ & Diameter $(\mathrm{m})$ & Aspect ratio $(\mathrm{H} / \mathrm{D})$ & Weight $(\mathrm{kg})$ & Swept area $A\left(\mathrm{~m}^{2}\right)$ & Tip speed ratio at $4 \mathrm{~m} / \mathrm{s}$ \\
\hline Blade 1 & 0.46 & 0.46 & 1.00 & 0.34 & 0.217 & 0.88 \\
Blade 2 & 0.46 & 0.35 & 1.31 & 1.40 & 0.161 & 1.03 \\
Blade 3 & 0.39 & 0.29 & 1.34 & 0.44 & 0.113 & 0.81 \\
\hline
\end{tabular}

Figure 6 shows rotational speed of three blades in different wind speed. During the test, the wind turbine blades rotational speed varies from $72 \mathrm{rpm}$ to $241 \mathrm{rpm}$ and the upstream flow velocity varies from $2 \mathrm{~m} / \mathrm{s}$ to 4.4 $\mathrm{m} / \mathrm{s}$. This figure state that the system has better performance for Blade-2 and 3 . On the other hand, blade 1 showed low rotational speed. This may be due to the cause of slim rotor with small diameter which can get higher rotational speed but lower torque, and vice versa rotor with bigger rotational diameter produces a bigger torque but a lower rotational speed.

Figure 7 compares the theoretically calculated extracted power produced by the three different savonius rotors alone in different wind speed. Figure shows that the extracted power from the wind of the wind turbine blade mainly starts from $3 \mathrm{~m} / \mathrm{sec}$. Before that, power generation is very small. It largely increases when it turns from 3 to $4 \mathrm{~m} / \mathrm{sec}$. It also showed the variation of extracted power with available wind speed in air. This difference is due to the variation of swept area which has been already explained in Equation (3). Beside this, weight of turbine can play the role to change the extracted power with wind speed.

\section{Conclusion}

The average wind speed in coastal area of Bangladesh is not that much high (about $4 \mathrm{~m} / \mathrm{s}$ ). Hence, it can contribute effectively on our energy sectors depending on perfect designing and optimization of wind turbine. An advantage of VAWTs is that they can catch the wind from all directions and also can withstand much harsher environments. The paper presents the different designs of rotor and reveals the influence of design parameters on the mechanical performances of the rotor of wind turbines which can be used for small scale power generation. The experiments were carried out in wind tunnel using three different model turbines and performance was measured. The swept area and weight of the rotor can play an important role on the performance of rotor. The rotor with small diameter can get higher rotational speed but lower torque and lower power, and vice versa rotor with bigger rotational diameter produces a bigger torque and also extracts high power, but a lower rotational speed. Moreover, further accurate assembly and proper choosing of blade material will help to achieve better results. However, blades profile can be improved to have more aerodynamic rotation with an airfoil design and 


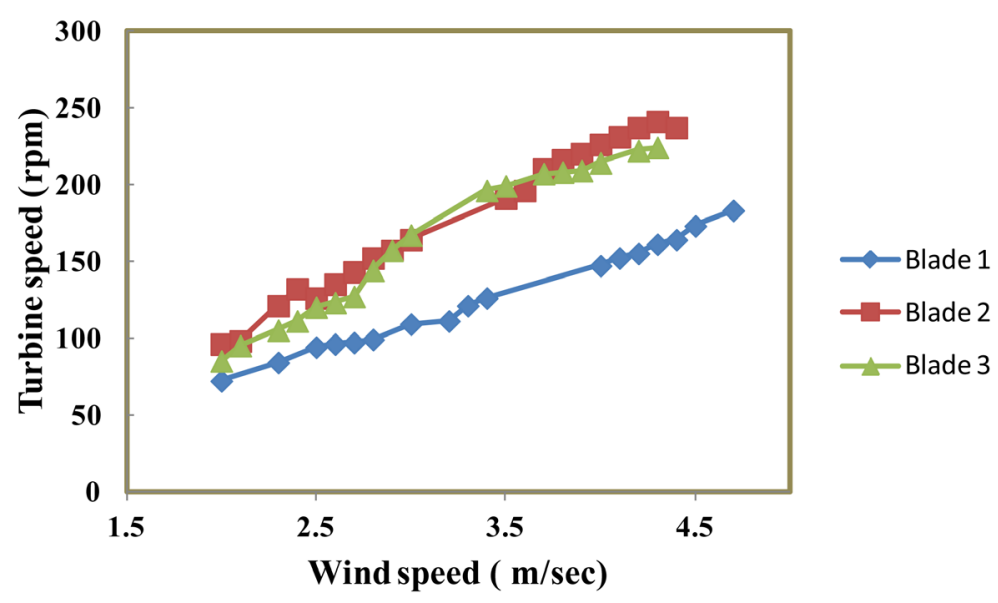

Figure 6. Data of rotational speed (rpm) for variation of wind speeds $(v)$.

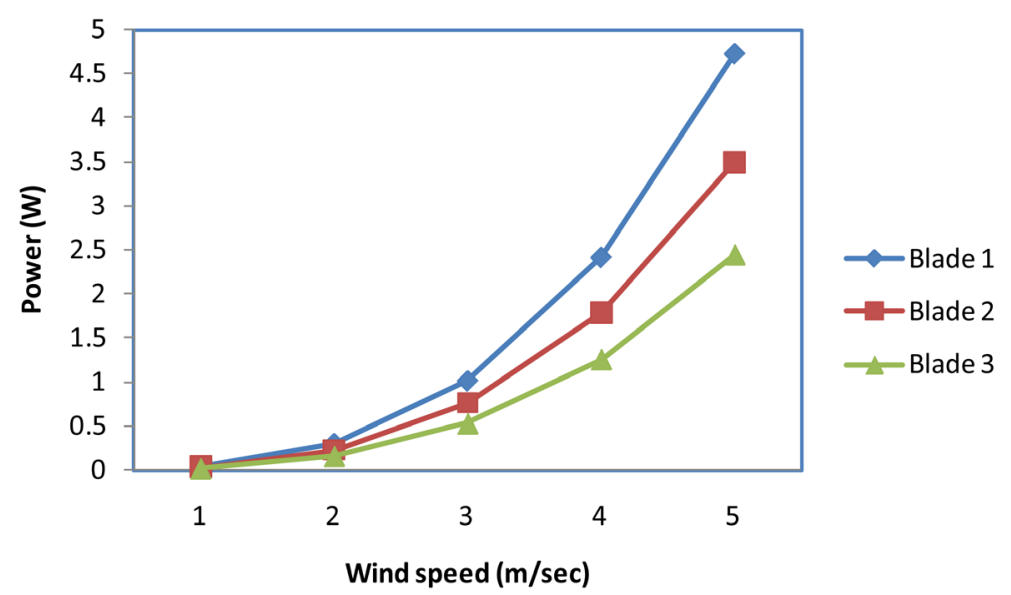

Figure 7. Power vs. wind speed curve.

providing a load can ensure a smoother result. Experimental results can be affected a bit while applying in coastal area with natural wind source and varying temperature as well.

\section{References}

[1] Ajedegba, J.O. (2008) Effects of Blade Configuration on Flow Distribution and Power Output a Zephyr Vertical Axis Wind Turbine. Thesis Submitted for a Degree of M.Sc. to University of Ontario Institute of Technology.

[2] Musgrove, P.J. (1987) Wind Energy Conversion: Recent Progress and Future Prospects. Solar \& Wind Technology, 4, 37-49. http://dx.doi.org/10.1016/0741-983X(87)90006-3

[3] Amirat, Y., Benbouzid, M.E.H., Bensaker, B. and Wamkeue, R. (2007) Condition Monitoring and Fault Diagnosis in Wind Energy Conversion Systems: A Review. IEEE International Electric Machines and Drives Conference, 2, 14341439.

[4] Ali, M.H. (2013) Experimental Comparison Study for Savonius Wind Turbine of Two \& Three Blades at Low Wind Speed. International Journal of Modern Engineering Research (IJMER), 3, 2978-2986.

[5] Hyers, R.W., McGowan, J.G., Sullivan, K.L., Manwell, J.F. and Syrett, B.C. (2006) Condition Monitoring and Prognosis of Utility Scale Wind Turbines. Energy Materials, 1, 187-203. http://dx.doi.org/10.1179/174892406X163397

[6] Kumar, A. and Grover, S. (1993) Performance Characteristics of a Savonius Rotor for Wind Power Generation-A Case Study, Alternate Sources of Energy. Proceedings of Ninth National Convention of Mechanical Engineers, IIT Kanpur.

[7] Ogawa, T., Yoshida, H. and Yokota, Y. (1989) Development of Rotational Speed Control Systems for a SavoniusType Wind Turbine. ASME Journal of Fluids Engineering, 111, 53-58. http://dx.doi.org/10.1115/1.3243598 
[8] Shankar, P.N. (1978) Development of Vertical Axis Wind Turbines. Rural Technology, IISc, Bangalore, 145-162.

[9] Widodo, W.S., Chin, A.C., Sihombing, H. and Yuhazri, M.Y. (2012) Design and Analysis of 5 kW Savonius Rotor Blade. Global Engineers \& Technologists Review, 2.

[10] Bennouna, O., Heraud, N., Rodriguez, M. and Camblong, H. (2007) Data Reconciliation and Gross Error Detection Applied to Wind Power. Proceedings of the Institution of Mechanical Engineers, Part I: Journal of Systems and Control Engineering, 221, 497-506. http://dx.doi.org/10.1243/09596518jsce266 